\title{
Do geopolitical risk and energy consumption contribute to environmental degradation? Evidence from E7 countries
}

\author{
Muhammad Iftikhar ul Husnain ${ }^{1} \cdot$ Qasim Raza Syed ${ }^{2} \cdot$ Arooj Bashir $^{3} \cdot$ Muhammad Aamir Khan $^{1}$
}

Received: 18 April 2021 / Accepted: 14 November 2021 / Published online: 30 January 2022

(c) The Author(s), under exclusive licence to Springer-Verlag GmbH Germany, part of Springer Nature 2021

\begin{abstract}
Environmental degradation is frequently cited as one of the eminent issues in the modern era. To limit environmental degradation, prior literature discerns several macroeconomic, socio-economic, and institutional factors that affect environmental degradation. However, the relationship between geopolitical risk and environmental degradation is understudied in the previous literature. To fill this gap, the inquiry at hand aims to scrutinize the influence of geopolitical risk on environmental degradation for E7 countries while controlling the effect of renewable energy, non-renewable energy, and GDP. Further, we utilize both the ecological footprint and $\mathrm{CO}_{2}$ emissions as proxies of environmental degradation and employ secondgeneration panel methods for robust findings. In addition to this, the present study uses augmented mean group (AMG) estimator to provide long-run relationship among the selected variables. The findings from the AMG estimator expound that there exists environmental Kuznets curve (EKC) for E7 countries. Moreover, renewable energy ameliorates environmental quality because it plunges both ecological footprint and $\mathrm{CO}_{2}$ emissions. On the contrary, non-renewable energy consumption escalates both ecological footprint and $\mathrm{CO}_{2}$ emissions. Finally, geopolitical risk tends to decrease $\mathrm{CO}_{2}$ emissions as well as ecological footprint. Our findings deduce a few policy implications to replenish environmental quality. For instance, the share of renewables in the energy mix should be surged to ameliorate the environmental quality. Further, to control both the geopolitical risk and environmental degradation at the same time, policymakers should put forward reforms and initiatives (e.g., policies to escalate R\&D, technological innovations, and tax exemptions on imports of renewables) that can help to improve environmental quality without affecting geopolitical risk. At times of low geopolitical risk, environmental degradation will surge; therefore, the rate of environmental control taxes should be increased by the policymakers.
\end{abstract}

Keywords Ecological footprint $\cdot \mathrm{CO}_{2}$ emissions $\cdot$ Geopolitical risk $\cdot$ Renewable energy $\cdot$ Non-renewable energy $\cdot$ Augmented mean group estimator

\section{Introduction}

Responsible Editor: Eyup Dogan

Qasim Raza Syed

qasimrazasyed.economics@gmail.com

Muhammad Iftikhar ul Husnain

iftikharhusnain@comsats.edu.pk

Arooj Bashir

arooj_bashir69@yahoo.com

Muhammad Aamir Khan

m.aamir.khan@comsats.edu.pk

1 Department of Economics, COMSATS University Islamabad, Islamabad, Pakistan

2 Universiti Sains Malaysia, Penang, Malaysia

3 COMSATS University Islamabad, Islamabad, Pakistan
The growing number of state and regional instability, energy crisis, terrorist attacks, political copes, and other unfavorable events worldwide has aggravated the issue of geopolitical risk. Geopolitical risk (GPR) is referred to tensions linked with terrorism, wars, and unfriendly relations among countries (Adams et al. 2020) and is important to the economies susceptible to wars or war-like tensions, terrorism, ethnicity, conflict, and political violence. Furthermore, major geopolitical events such as 9/11, London bombing, Madrid bombing, Bombay attacks, China-USA trade war, Korea's nuclear issues, and Iranian trade tensions all pose a serious threat to the economic stability of a country (Cai and Wu 2020). Geopolitical risk can affect economic performance and investment decisions and trigger business cycles that 
impact natural resource rents and financial markets (PricewaterhouseCoopers 2018; Balcilar et al. 2018; Dogan et al. 2021). Unfavorable geopolitical events change the direction of investment spending towards less productive uses like reconstruction and security (Olanipekun and Alola 2020). Moreover, extreme geopolitical events will cause panic among investors and businesses that will create abnormal fluctuations in the market and eventually influence energy returns and volatility (Qin et al. 2020). Subsequently, GPR is considered as one of the top five business threats globally (Price Waterhouse Coopers 2018). Recently, Syed et al. (2021) highlight that geopolitical risk also exerts detrimental impacts on tourism.

Geopolitical events have a harmful consequence not only on social and economic life but also on the environment. Anser et al. (2021a) put forward two theoretical channels that link GPR and the environment. The first channel is called the "escalating effect" which describes that GPR mitigates renewable energy consumption (hereafter REC) which in turn leads to higher carbon emissions. Parallel to this, the "mitigating effect" expounds that GPR curtails non-renewable energy consumption (hereafter NREC) and economic growth leading to a reduction in $\mathrm{CO}_{2}$ emissions. In another study, Anser et al. (2021b) pointed out that GPR affects economic growth, $R \& D$ investment, innovations, technological advancements, and investment in clean energy. These aforementioned indicators eventually escalate emissions. Therefore, GPR may either curb or surge carbon emissions.

Based on the above milieu, this research contributes to the existing empirical literature by exploring the impact of GPR, economic growth, NREC, and REC on environmental degradation. To attain this, firstly, we use the recently introduced GPR index developed by Caldara and Iacoviello (2018). Despite the significance of the prior studies and their results, the proxies of geopolitical events (e.g., terrorism/ terrorist attacks, war or militarization, and political instability) have some limitations of not in real-time, being discontinuous, and not covering the real geopolitical events. Moreover, these proxies do not accurately describe GPR as they do not account for all events, ranging from economic crisis to wars to climate change (Bouoiyour et al. 2019). The GPR index captures the risk associated with terror attacks, military threats, war risk, political tensions, and geopolitical uncertainty. This index is superior to other indicators as it offers a time-consistent, holistic, and real-time approach to capture GPR. Moreover, the GPR index integrates both present and expected future risks (Muhammad and Long 2021).

Secondly, many countries aim to achieve the goal of energy security for the smooth functioning of their economies and easy access of their people to modern and clean energy supplies (Ayoo 2020). Economic, social, and human well-being depends on the production of goods which further depend on the availability of energy (Bompard et al.
2017). It is a well-established fact that economic growth and well-being are closely correlated (Warr and Ayers 2010). A plethora of energy challenges including high energy prices, uncertain energy supplies, environmental degradation, and inadequate supplies of energy sources are being faced by both developed and developing economies. Countries with high reliance on energy imports are vulnerable to risks and threats associated with energy supplies (Yergin 2006). E7 countries, with their ever-increasing energy demand due to population growth and robust economic expansion, heavily depend on energy imports to reduce poverty and to uplift the well-being of their people. Therefore, economic security which is strongly correlated with energy security remains a challenge for E7 countries.

Thirdly, the study focuses on E7 countries (Brazil, China, Indonesia, India, Mexico, Turkey, and Russia), which according to Earth System Science Data (ESSD) (2020) emit approximately $45 \%$ of global $\mathrm{CO}_{2}$ emissions. Four of the world's highest $\mathrm{CO}_{2}$ emitter countries (China, India, Russia, and Indonesia) are part of this group. A high level of growth and the consequent high energy consumption in these economies cause a substantial increase in $\mathrm{CO}_{2}$ emissions. Moreover, these countries are strong political powers, and they have political tensions as well. According to Global Risks Report (2021), E7 countries are among the most critical countries based on their socio-economic and geopolitical conditions. For instance, being the second largest economy and most populated country in the world, China has been an important political economy that might affect the whole world. Moreover, the China-USA trade war has been one of the prime reasons behind the geopolitical tensions between these countries that have led to global tensions worldwide. Further, border tensions between China and India exert pressure on both countries which in turn affect the social and economic life of consumers and producers of both countries. Brazil has disputes with Uruguay and Colombia on smuggling and immigration. Moreover, unstable governments and impeachments contribute to geopolitical instability in the case of Brazil. As mentioned earlier, India has a long history of border tensions with its neighbors such as China and Pakistan. Also, the world has witnessed several wars between India and its neighbors which have created spikes in geopolitical tensions. Further, following the USA and UK, India is the third country with the highest number of cyber-attacks in the last two decades. Likewise, Mexico, Turkey, and Russia have been facing several issues with the USA and a few other countries. E7 economies have border tensions with their neighbors, and they also have (geo)political instability that contributes to economic uncertainty. It is worth mentioning that, according to the Global Risks Report (2021), COVID-19 has been exerting a detrimental impact on the economies of E7 countries which have experienced even negative economic growth during the COVID-19 pandemic. 
Moreover, due to lockdowns and other stringency measures, the energy sector has also witnessed a negative supply shock that has led to the high vulnerability of the energy sector.

Fourthly, we employ a comprehensive measure of environmental degradation, i.e., ecological footprint (hereafter $\mathrm{EF}$ ) along with $\mathrm{CO}_{2}$ emissions to have more robust and insightful conclusions. Fifthly, we have disaggregated energy consumption by source, NREC, and REC, to see their separate role in escalating environmental degradation in anticipation of GPR. Finally, to overcome the problem of heterogeneity and cross-sectional dependency, the present study uses the second generation of panel data methods. In addition to this, we also employ CIPS unit root tests, Westerlund cointegration test, and augmented mean group (AMG) estimator to render robust and consistent estimates in the existence of cross-sectional dependence and heterogeneity (Baloch and Wang 2019).

\section{Literature review}

Environmental pollution has been the core of empirical as well as theoretical discussion for many years until now. (Dahish and Recep 2020).

Based on the GPR index presented by Caldara and Iacoviello (2018), the role of GPR on energy consumption and environmental degradation has been explored by a few studies in recent years. In the case of Russia, Rasoulinezhad et al. (2020) tested the relationship between energy transition and GPR from 1993 to 2018 . They detected a positive influence of GPR, $\mathrm{CO}_{2}$ emissions, financial openness, and exchange rate on energy transition, whereas the economic growth, inflation rate, and population growth negatively affect the energy transition. Moreover, the relationship between economic growth, energy transition, $\mathrm{CO}_{2}$ emissions, inflation rate, and population growth is negative in the short run. On the contrary, financial openness, GPR, and exchange rate accelerate the energy transition. Their results further revealed that in the short run, GPR is the main contributor to the energy transition. Recently, Alsagr and Hemmen (2021) explored the dynamic impact of GPR and financial development on REC during 1996-2015 in 19 emerging economies. The results of GMM revealed a positively significant influence of financial development on energy consumption. Similarly, in the case of the USA, Sweidan (2021) concluded that GPR has a statistically significant and positive effect on energy diffusion. It implies that GPR drives energy rather than depressing it.

Adams et al. (2020) investigated the relationship between economic policy uncertainty and NREC for 10 resourcerich economies with a high level of GPR from 1996 to 2017 in the long run. The findings of Kao's test reveal a cointegration association among GPR, NREC, economic policy uncertainty, economic growth, and $\mathrm{CO}_{2}$ emissions. Moreover, the PMG-ARDL results show that uncertainty, economic growth, and NREC contribute to CO2 emissions. This indicates that economic policy uncertainty has a detrimental impact on the environment. They found a significant relationship between uncertainty and emissions in the long run. Lastly, the results of the DH causality test show a oneway causal relationship running from $\mathrm{CO}_{2}$ emissions to GPR and a two-way causal relationship among $\mathrm{CO}_{2}$ emissions and NREC, economic growth and $\mathrm{CO}_{2}$ emissions, and economic policy uncertainty and $\mathrm{CO}_{2}$ emissions.

Likewise, Anser et al. (2021a) probe the effect of GPR on the EF in the case of BRMCC (Brazil, Russia, Mexico, China, Colombia) using AMG estimators. The study concludes that GPR mitigates environmental degradation. Zhao et al. (2021) examined the asymmetric impact of GPR on carbon emissions in the case of BRICS countries using the NARDL approach. The findings from the study reveal that the impact of GPR on carbon emissions is asymmetric, and it is heterogeneous across the BRICS countries. Anser et al. (2021b) estimated the impact of GPR, REC, NREC, economic growth, population, and economic growth on $\mathrm{CO}_{2}$ emissions in BRICS countries. They employed the second-generation analysis and AMG estimator. The results indicate that GPR, GDP, population, and NREC escalate $\mathrm{CO}_{2}$ emissions and REC reduces emissions in BRICS. It is worth mentioning that prior studies on the GPR-environment nexus either use $\mathrm{CO}_{2}$ emissions or EF as a proxy for environmental degradation. Next, no study expounds on the renewable energy-environment and non-renewable energy-environment nexus amidst GPR. However, we employ both $\mathrm{CO}_{2}$ emissions and $\mathrm{EF}$ as a proxy for the environment. Recently, Hashmi et al. (2021) use global emissions and GPR to explore the worldwide nexus between GPR and emissions. They note that GPR is a key determinants of global carbon emissions.

It is important to know that risk due to the COVID-19 pandemic has also affected both energy and the environment. For instance, Iqbal et al. (2021) revealed that the COVID-19 outbreak mitigates both NREC and carbon emissions. In the case of India, Aruga et al. (2020) conclude that lockdown amid the COVID-19 outbreak plunges NREC. Algamdi et al. (2021) find that the COVID-19 outbreak impedes oil prices. Additionally, Wang and Su (2020) reported that the COVID-19 outbreak decreases NREC and hence improved the environmental quality in China. In the case of India, Lokhandwala and Gautam (2020) conclude that the COVID19 outbreak improved both air and water quality. So, it could be perceived that the risk associated with COVID-19 has a positive effect on energy security and environmental quality (Table 1). 


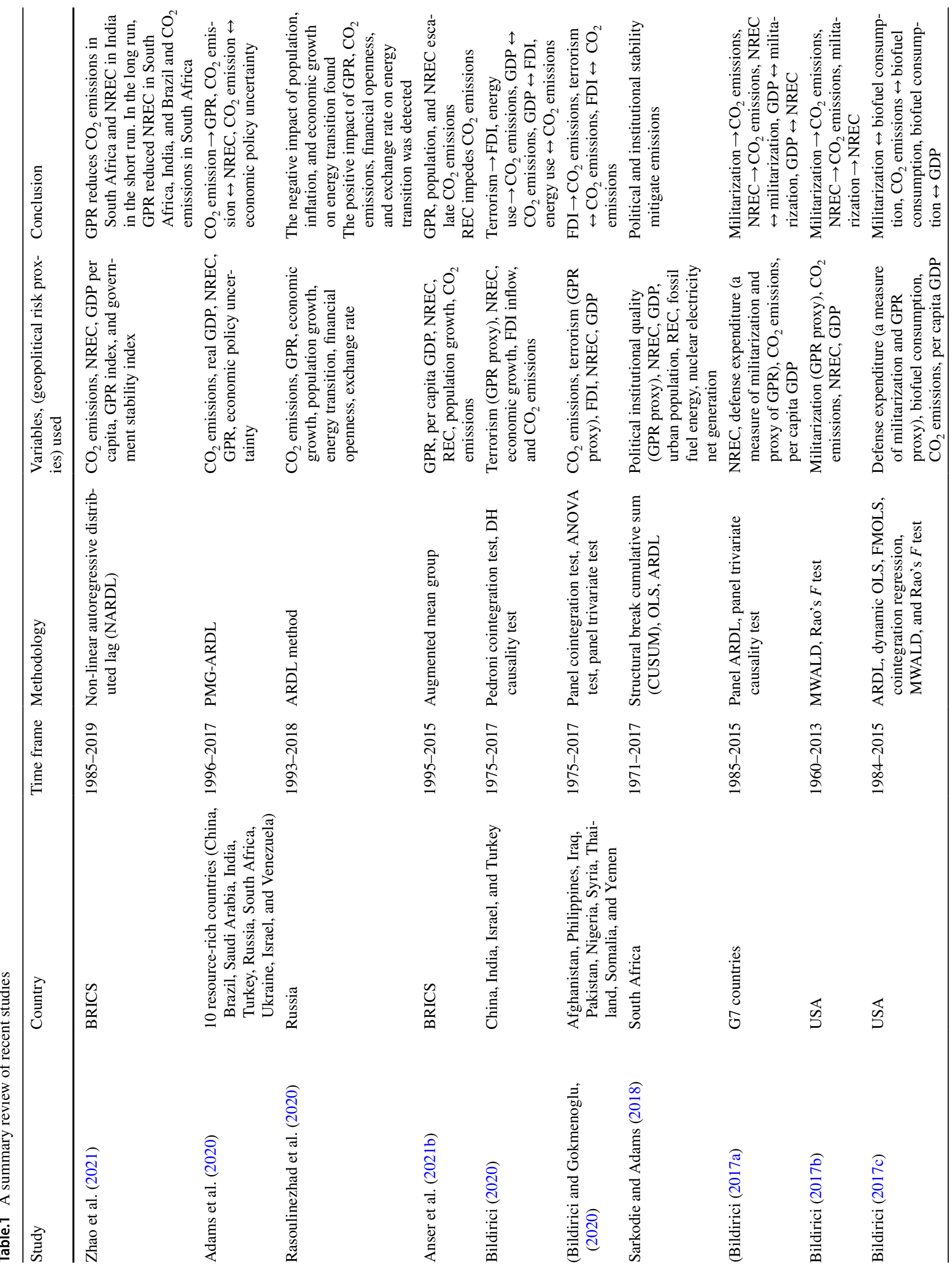




\section{Model and methods}

In the literature of environmental economics, several empirical models have been developed to link the environment with the economy. It is worth noting that the EKC hypothesis has been regarded as the most critical theory of environmental economics that has been extensively tested in empirical studies. The EKC is an inverted U-shaped relationship between environment and income, and, in this analysis, we extend the EKC framework by including GPR and energy consumption:

$\mathrm{CO}_{2}=f\left(G D P, G D P^{2}, N R E C, R E C, G P R I\right)$

$E F=f\left(G D P, G D P^{2}, N R E C, R E C, G P R I\right)$

In Eqs. (1) and (2), GDP and GDP ${ }^{2}$ denote real GDP per capita and square of real GDP per capita, respectively. NREC and REC represent non-renewable energy consumption and renewable energy consumption, respectively. Further, GPRI is the geopolitical risk index. $\mathrm{CO}_{2}$ is carbon dioxide emissions, whereas $\mathrm{EF}$ is the ecological footprint. These aforementioned variables $\left(\mathrm{CO}_{2}\right.$ and $\left.\mathrm{EF}\right)$ are employed as an environmental degradation proxy. It is hypothesized that the magnitude of the coefficient of GDP and $\mathrm{GDP}^{2}$ is $>0$ and $<0$, respectively. This means that EKC does exist, implying that, at the initial stages of economic growth, environmental degradation also increases and decreases as economic growth exceeds a certain point. Several recent studies use the EKC framework to explore the determinants of environmental degradation (see, for example, Destek and Sarkodie 2019; Syed and Bouri 2021; Haider et al. 2020). In addition to this, we further hypothesized that the coefficient of NREC and REC is $>0$ and $<0$, respectively. This indicates that non-renewable energy escalates environmental degradation, while renewable energy impedes it (see, for example, Anser el al. 2021c; Bhowmik et al. 2021; Ali et al. 2020; Gardiner and Hajek 2020). Next, it is hypothesized that the coefficient of GPRI is $<0$, depicting that GPR plunges the environmental degradation (see, for example, Adams et al. 2020). It is stated that this outcome is possible if the mitigating effect exceeds escalating effect.

The present study utilizes an annual panel dataset for E7 economies (Brazil, China, India, Indonesia, Mexico, Russia, and Turkey) over the period 1990-2015. The dependent variables are $\mathrm{CO}_{2}$ emissions (measured in metric tons per capita) and ecological footprint (measured in Gha per person). On the other hand, independent variables are real GDP per capita (GDP), NREC, REC, and GPR index (GPRI). GPRI is established by Caldara and Iacoviello (2018), which is calculated based on the frequency of the newspaper articles containing the words, for example, "geopolitics," "geopolitical risk," and "geopolitical 
Table.2 Descriptive statistics

\begin{tabular}{lcccccc}
\hline & $E F$ & $C O 2$ & $G D P$ & $N R E C$ & $R E C$ & $G P R I$ \\
\hline Mean & 6.381 & 1.655 & 13.221 & 10.282 & 2.012 & 7.991 \\
St. Dev & 0.435 & 0.311 & 0.272 & 0.224 & 0.192 & 0.101 \\
Kurtosis & 2.113 & 1.983 & 1.873 & 2.322 & 2.465 & 3.284 \\
Skewness & -0.100 & -0.091 & -0.171 & -0.212 & -0.161 & 0.132 \\
Jarque-Bera & $(0.001)^{* * *}$ & $(0.004)^{* * *}$ & $(0.002)^{* * * *}$ & $(0.002)^{* * *}$ & $(0.004)^{* * *}$ & $(0.003)^{* * *}$ \\
\hline
\end{tabular}

Table.3 Cross-sectional dependence test

\begin{tabular}{llll}
\hline & $\begin{array}{l}\text { Breusch-Pagan } \\
\text { LM }\end{array}$ & Pesaran scaled LM & Pesaran CD \\
\hline $\mathrm{CO}_{2}=\mathrm{f}(\mathrm{GDP}$, & $(17.010)$ & $(12.052)$ & $(4.170)$ \\
$\mathrm{REC}$, & {$[0.001]^{* * *}$} & {$[0.001]^{* * * *}$} & {$[0.002]^{* * *}$} \\
$\mathrm{NREC}$, & & & \\
GPRI) & & $(17.513)$ & $(5.752)$ \\
$\mathrm{EF}=\mathrm{f}(\mathrm{GDP}$, & $(15.311)$ & {$[0.001]^{* * *}$} & {$[0.002]^{* * *}$} \\
$\mathrm{REC}$, & {$[0.001]^{* * *}$} & & \\
NREC & & & \\
GPRI) & & & \\
\hline
\end{tabular}

(.) indicates $t$ statistics, whereas [.] shows $P$ values. *, **, and *** represent $10 \%, 5 \%$, and $1 \%$ levels of significance, respectively.

tension. The summary of data is given in Table 10 in the Appendix. In addition, we employ several cross-sectional dependence tests, second-generation unit root tests, second-generation cointegration tests, and augmented mean group (AMG) estimator for robust analysis.

Table 2 exhibits the descriptive statistics of study variables. The mean value of GDP is the highest, whereas it is the lowest for $\mathrm{CO}_{2}$ emissions. Also, the standard deviation is the highest for EF, while it is the minimum for GPRI. Moreover, GPRI is positively skewed. while all other variables are negatively skewed. In addition to this, Jarque-Bera test statistics highlight that the selected dataset follows the non-normal distribution.

All variables are transformed into logarithmic form. (.) denotes $P$ value. Further, ***, **, and * represent $1 \%, 5 \%$, and $10 \%$ levels of significance, respectively.

\section{Results and discussion}

\section{Results}

To achieve its objective (i.e., probing the impact of GPR, NRE, and REN on the environment), in this section, the current study reports the results from second-generation panel data methods and AMG estimators coupled with the panel causality test. First, we report the results of the Breusch-Pagan LM test, the Pesaran LM test, and the Pesaran CD test in Table 3.
Table.4 Findings from CIPS test

\begin{tabular}{llllll}
\hline Variable & \multicolumn{2}{l}{ CIPS test } & & \multicolumn{2}{l}{ CADF test } \\
\cline { 2 - 3 } \cline { 5 - 6 } & $I(0)$ & $I(1)$ & & $I(0)$ & $I(1)$ \\
\hline $\mathrm{CO}_{2}$ & -1.010 & $-2.881 * * *$ & -2.131 & $-3.325 * * *$ \\
$E F$ & -2.132 & $-3.635 * * *$ & -1.932 & $-3.783 * * *$ \\
$G D P$ & -0.791 & $-2.712^{* * *}$ & & -2.071 & $-2.646 * * *$ \\
$N R E C$ & -1.563 & $-2.609 * * *$ & & -2.484 & $-4.182^{* * *}$ \\
$R E C$ & -0.931 & $-2.985 * * *$ & -1.462 & $-3.368 * * *$ \\
$G P R I$ & -2.327 & $-3.821 * * *$ & -1.396 & $-2.591 * * *$ \\
\hline
\end{tabular}

The critical value of CIPS at $1 \%$ is -2.51 , whereas the critical value of CADF at $1 \%$ is -2.57 .

Table.5 Results from Westerlund test

\begin{tabular}{|c|c|c|c|c|}
\hline \multicolumn{5}{|c|}{$\mathrm{CO}_{2}=\mathrm{f}\left(\mathrm{GDP}, \mathrm{GDP}^{2}, \mathrm{REC}, \mathrm{NREC}, \mathrm{GPRI}\right)$} \\
\hline Statistic & Value & $Z$ value & $P$ value & Bootstrap $P$ value \\
\hline $\mathrm{G}_{\mathrm{t}}$ & -3.321 & -3.092 & $0.002 * * *$ & $0.002 * * *$ \\
\hline $\mathrm{G}_{\mathrm{a}}$ & -4.252 & -5.363 & $0.001 * * *$ & $0.001 * * *$ \\
\hline $\mathrm{P}_{\mathrm{t}}$ & -5.471 & -6.331 & $0.011 * * *$ & $0.001 * * *$ \\
\hline $\mathrm{P}_{\mathrm{a}}$ & -4.124 & -4.933 & $0.001 * * *$ & $0.001 * * *$ \\
\hline \multicolumn{5}{|c|}{$\mathrm{EF}=\mathrm{f}\left(\mathrm{GDP}, \mathrm{GDP}^{2}, \mathrm{REC}, \mathrm{NREC}, \mathrm{GPRI}\right)$} \\
\hline Statistic & Value & $Z$ value & $P$ value & Bootstrap $P$ value \\
\hline $\mathrm{G}_{\mathrm{t}}$ & -3.132 & -3.591 & $0.002 * * *$ & $0.002 * * *$ \\
\hline $\mathrm{G}_{\mathrm{a}}$ & -4.411 & -5.357 & $0.001 * * *$ & $0.001 * * *$ \\
\hline $\mathrm{P}_{\mathrm{t}}$ & -5.142 & -6.423 & $0.011 * * *$ & $0.001 * * *$ \\
\hline $\mathrm{P}_{\mathrm{a}}$ & -3.513 & -3.832 & $0.003 * * *$ & $0.003 * * *$ \\
\hline
\end{tabular}

Null hypothesis of the Westerlund test indicates that there is no cointegration among the variables. In addition, $* * *, * *$, and $*$ report $1 \%$, $5 \%$, and $10 \%$ levels of significance, respectively.

The null hypothesis of all $\mathrm{CD}$ tests describes that there is no cross-sectional dependence (CD). The findings from $\mathrm{CD}$ tests reveal that at $1 \%$ level of significant, null hypothesis could be rejected, indicating that there exists $\mathrm{CD}$ in our case. This implies that shocks in one country can transmit to another country. Next, we test unit root in all selected variables to identify the order of integration. The results from the CIPS unit root test of Pesaran (2007) are given in Table 4.

We fail to reject the null hypothesis of "there is no unit root at $I(0)$." However, at a $1 \%$ level of significance, we could reject the null hypothesis at $I(1)$. This specifies that 
Table.6 Long-run estimates from AMG estimator

\begin{tabular}{|c|c|c|c|c|}
\hline \multirow[b]{2}{*}{ Variable } & \multicolumn{4}{|c|}{$\mathrm{CO}_{2}$ emissions } \\
\hline & Coefficient & St. error & $Z$ stat & $P$ value \\
\hline$G D P$ & 0.211 & 0.220 & 2.669 & $(0.003)^{* * *}$ \\
\hline$G D P 2$ & -0.060 & 0.122 & -3.213 & $(0.002)^{* * *}$ \\
\hline NREC & 0.171 & 0.330 & 2.851 & $(0.003)^{* * *}$ \\
\hline$R E C$ & -0.094 & 0.121 & -3.202 & $(0.002)^{* * *}$ \\
\hline$G P R$ & -0.082 & 0.212 & -2.694 & $(0.002)^{* * *}$ \\
\hline Constant & 0.011 & 0.121 & 0.091 & $(0.921)$ \\
\hline RMSE (sigma) & 0.0171 & & & \\
\hline Wald test & $(0.001)^{* * *}$ & & & \\
\hline
\end{tabular}

*** represents the level of significance at $1 \%$. (.) denotes $P$ value.

all selected variables are integrated of order 1 . In Table 5, the results of the Westerlund (2007) test of cointegration are shown. The test consists of four different test statistics, and the null hypothesis of all these statistics postulates that cointegration does not exist.

We employ ecological footprint (EF) and carbon dioxide emissions $\left(\mathrm{CO}_{2}\right)$ as a proxy for environmental degradation, hence applying Westerlund (2007) test two times. We do not fail to reject the null hypothesis, which indicates that there is no cointegration among the selected variables. Hence, we can conclude that there is an existence of cointegration among the selected variables used in the model.

Further, Westerlund (2007) test does not render long-run estimates (elasticities); therefore, we apply the AMG estimator to avail long-run estimates. The findings of the AMG estimator using $\mathrm{CO}_{2}$ emissions as environmental degradations' proxy are reported in Table 6.

In Table 6, all reported variables are statistically significant. Further, the sign of GDP and GDP ${ }^{2}$ is positive and negative, respectively. Therefore, we note the validity of EKC for E7 countries. This outcome is in line with the conclusion of Anser et al. (2021b). Next, the value of NREC is 0.17 , indicating that a $0.17 \%$ upsurge in carbon emissions is fostered by a $1 \%$ raise in NREC. Therefore, we conclude that NREC escalates emissions. This finding conforms with the results reached by Gardiner and Hajek (2020). Additionally, the value of REC is -0.09 , implying that a $1 \%$ rise in REC plunges $\mathrm{CO}_{2}$ emissions by $0.09 \%$. This means that REC reduces $\mathrm{CO}_{2}$ emissions in E7 countries (Alola et al. 2019). The coefficient of GPRI is -0.08 , indicating that a $0.08 \%$ decrease in $\mathrm{CO}_{2}$ emissions is fostered by a $1 \%$ surge in GPRI. There are a few possible reasons behind the negative impact of GPRI on $\mathrm{CO}_{2}$ emissions. First, high GPRI may discourage consumption and production, which sequentially impedes $\mathrm{CO}_{2}$ emissions. Second, GPRI could affect energy prices, international trade, and tourism activities. These factors may constraint $\mathrm{CO}_{2}$ emissions. Our findings are also
Table.7 Results from AMG estimator

\begin{tabular}{lclll}
\hline & & \multicolumn{3}{l}{ Ecological footprint } \\
\cline { 3 - 5 } Variable & Coefficient & St. error & $Z$ stat & $P$ value \\
\hline$G D P$ & 0.171 & 0.243 & 4.581 & $(0.001)^{* * *}$ \\
GDP2 & -0.050 & 0.136 & -3.553 & $(0.002)^{* * *}$ \\
NREC & 0.131 & 0.221 & 4.512 & $(0.001)^{* * *}$ \\
REC & -0.024 & 0.143 & -3.612 & $(0.002)^{* * *}$ \\
GPRI & -0.107 & 0.127 & -3.001 & $(0.002)^{* * *}$ \\
Constant & -0.11 & 7.501 & 0.852 & $(0.394)$ \\
RMSE (sigma) & 0.0271 & & & \\
Wald test & $(0.002)^{* * *}$ & & & \\
\hline
\end{tabular}

*** represents the level of significance at $1 \%$

backed by the study of Adams et al. (2020) and Anser et al. (2021a) who noted that GPR impedes environmental degradation. However, our findings are inconsistent with the conclusion of Anser et al. (2021b) who reported that GPR leads to higher carbon emissions.

Likewise, we use EF as a proxy for environmental degradation and scrutinize the impact of REC, NREC, and GPRI employing an AMG estimator. The estimates are reported in Table 7.

Table 7 depicts that all coefficients are statistically significant. Next, the GDP and GDP ${ }^{2}$ coefficients are positive and negative, respectively. Thus, we validate the presence of EKC which is an inverse U-shaped relationship between income and environment. This outcome is supported by the conclusion of Destek et al. (2018). Additionally, the value of NREC is 0.13 , explaining that a $1 \%$ rise in NREC surges EF by $0.13 \%$. This conclusion is in line with the conclusion reached by Destek and Sinha (2020). On the contrary, the coefficient of REC is -0.02 implying that a $0.02 \%$ decrease in $\mathrm{EF}$ is fostered by a $1 \%$ increase in REC. Additionally, the value of GPRI is -0.10 inferring that a $1 \%$ upsurge in GPR impedes EF by $0.10 \%$. As mentioned earlier, a decrease in production and consumption activities due to high GPR could be the possible reason behind low levels of EF. This result is supported by Adams et al. (2020) who argue that GPR plunges environmental degradation.

Finally, we employ the DH causality test to examine the direction of causality. The findings of the DH test are reported in Tables 8-9.

As can be seen from Table 8, there exists one-way causality running from GDP to carbon emissions. Next, one-way causality is also running from GPRI to $\mathrm{CO}_{2}$ emissions. Likewise, one-way causality is running from $\mathrm{CO}_{2}$ emissions to NREC, from GDP to NREC, from REC to GDP, from REC to GPRI, and from NREC energy to REC.

According to Table 9, there exists unidirectional causality running from NREC to GDP, from REC to GDP, from NREC to GPRI, from GPRI to EF, from NREC to EF, and 
Table.8 Findings from DH causality test using CO2 emissions as a proxy for environment

\begin{tabular}{|c|c|c|c|}
\hline Null hypothesis & $W$ stat & Zbar stat & Prob \\
\hline $\mathrm{GDP}=>\mathrm{CO} 2$ & 2.48881 & 2.02459 & $0.0429 * *$ \\
\hline $\mathrm{CO} 2=>\mathrm{GDP}$ & 0.56538 & -0.77937 & 0.4358 \\
\hline $\mathrm{GPRI}=>\mathrm{CO} 2$ & 6.02583 & 7.18082 & 7.E-13*** \\
\hline $\mathrm{CO} 2=>\mathrm{GPRI}$ & 0.90403 & -0.28568 & 0.7751 \\
\hline $\mathrm{NREC}=>\mathrm{CO} 2$ & 1.31691 & 0.31621 & 0.7518 \\
\hline $\mathrm{CO} 2=>\mathrm{NREC}$ & 5.87251 & 6.95731 & 3.E-12*** \\
\hline $\mathrm{REC}=>\mathrm{CO} 2$ & 2.04930 & 1.38387 & 0.1664 \\
\hline $\mathrm{CO} 2=>\mathrm{REC}$ & 2.04357 & 1.37553 & 0.1690 \\
\hline $\mathrm{GPRI}=>\mathrm{GDP}$ & 0.76339 & -0.49071 & 0.6236 \\
\hline $\mathrm{GDP}=>\mathrm{GPRI}$ & 2.05134 & 1.38685 & 0.1655 \\
\hline $\mathrm{NREC}=>\mathrm{GDP}$ & 4.58700 & 5.08331 & 4.E- $07 * * *$ \\
\hline $\mathrm{GDP}=>\mathrm{NREC}$ & 1.84262 & 1.08259 & 0.2790 \\
\hline $\mathrm{REC}=>\mathrm{GDP}$ & 3.50567 & 3.50696 & $0.0005 * * *$ \\
\hline $\mathrm{GDP}=>\mathrm{REC}$ & 1.54096 & 0.64282 & 0.5203 \\
\hline $\mathrm{NREC}=>$ GPRI & 1.83005 & 1.06425 & 0.2872 \\
\hline GPRI $=>$ NREC & 1.69667 & 0.86983 & 0.3844 \\
\hline REC $=>$ GPRI & 3.30901 & 3.22027 & $0.0013 * * *$ \\
\hline $\mathrm{GPRI}=>\mathrm{REC}$ & 0.33797 & -1.11088 & 0.2666 \\
\hline $\mathrm{REC}=>\mathrm{NREC}$ & 2.03659 & 1.36535 & 0.1721 \\
\hline $\mathrm{NREC}=>\mathrm{REC}$ & 5.04578 & 5.75211 & 9.E-09*** \\
\hline
\end{tabular}

from REC to EF. Moreover, there exists bi-directional causality between EF and GDP, REC and GPRI, and between REC and NREC.

\section{Discussion}

We first scrutinize the CD in the selected set of panel data, since it is essential for reliable results. The outcomes from these approaches confirm the null hypothesis rejection at a $1 \%$ significance level; therefore, variables endure $\mathrm{CD}$. That means EF, $\mathrm{CO}_{2}$, GDP, NREC, REC, and GPRI shocks in one country are also correlated with other countries. In this way, due to interdependency between countries, economic shocks have spillover effects via trade channels (Bello et al. 2018). It has been observed that a shock in one of the E7 countries will transmit to other countries. For instance, the COVID-19 pandemic (i.e., originated from China) has been spread to other countries. This result is consistent with the findings of Dogan and Seker (2016) who report similar findings for top renewable energyconsuming countries; Sharif et al. (2019) for 74 nations; Destek and Sinha (2020) for 24 OECD economies; Danish et al. (2020) for BRICS countries; Nathaniel and Khan (2020) for ASEAN countries; Le and Bao (2020) for Latin America, the Caribbean emerging markets, and developing economies; Inglesi-Lotz and Dogan (2018) for SubSaharan Africa; Hacıimamoğlu and Sandalcılar (2020) for
35 developed and developing countries; and Sharma et al. (2021) for eight developing economies of Asia.

The Westerlund (2007) cointegration test illustrates that all variables in the current study are cointegrated (which proposes that there is an effective long-term connection among EF, $\mathrm{CO}_{2}$, GDP, NREC, REC, GPRI in E7 countries). The findings are in line with the results of Sharma et al. (2021) for eight developing countries of Asia, Sharif et al. (2019) for 74 nations, Le and Bao (2020) for 16 developing economies, Shafiei and Salim (2014) for OECD economies, and Zafar et al. (2019) for emerging economies. The longrun estimates from AMG show that NREC significantly promotes environmental degradation in E7 countries. The use of NREC exerts pressure on natural resources exploitations, and NREC emits higher carbon gas. As a result, environmental degradation occurs at a higher pace. The use of NREC still dominates in E7 countries; therefore, environmental degradation has been increasing over time. The results expound that a $1 \%$ raise in NREC fostered the emissions by $17 \%$. In the empirical literature, there is a predictable consent on the adverse environmental effect of NREC based on fossil fuel. Some respective studies including Gorus and Aydin (2019) for MENA countries; Nathaniel and Khan (2020), Tuna and Tuna (2019), and Hanif et al. (2019) for ASEAN countries; Sinha et al. (2017) and Sinha et al. (2019) for N-11 economies; Sharif et al. (2019) for 74 nations; Zhang et al. (2019) for BRICS countries; Nathaniel and Iheonu (2019) for subSaharan Africa; and Shahbaz et al. (2019) for Vietnam are similar to our findings. On the other hand, results depict that REC contributes significantly to environmental improvements in E7 countries. That is, a 1\% rise in REC tends to reduce $\mathrm{CO}_{2}$ emissions by $9 \%$. Renewables in the form of wind energy, hydropower energy, and solar energy, etc. do not emit greenhouse gases (e.g., CO2). Further, renewables do not exploit and deplete the natural resources and hence environmental degradation plunges. Since E7 countries are among the top countries that are shifting from NREC to REC, hence, they are at the right part by escalating the REC to achieve sustainable development. These findings are parallel with the conclusions attained by Al-Mulali and Ozturk (2015) for 23 selected European countries, Nathaniel and Khan (2020) for ASEAN countries, Sharif et al. (2019) for 74 nations, and Dogan and Aslan (2017) for EU countries. In contrast, our findings are inconsistent with the conclusions of Mehdi and Slim (2017) who report findings opposite to our conclusion for North African countries.

Furthermore, the results also indicate that a $1 \%$ hike in GPRI tends to reduce $\mathrm{CO}_{2}$ emissions by $8 \%$. GPRI adversely affects NREC and economic growth, which results in a decline in $\mathrm{CO}_{2}$ emissions. Also, GPRI affects economies through international trade, equity market, production and consumption, energy prices, military tensions, and war and terrorism. Further, GPRI is the main determinant of 
investment decisions and can alter financial and economic businesses because countries with secure political and social conditions witness a high level of investment. The change in investment decisions (due to GPRI) could be the reason behind the decline in the levels of $\mathrm{CO}_{2}$ emissions. It is worth reporting that the mitigating effect dominates the escalating effect in E7 countries, depicting that the net impact of GPR on the environment is negative. Although E7 countries have become the hub of GPR nowadays and they are being economically affected by GPR, GPR does not affect the environmental degradation in these countries. Our findings are compatible with Akadiri et al. (2020) Turkey, Kannadhasan and Das (2020) Asian emerging stock market, Balcilar et al. (2018) BRICS countries, Al Mamun et al. (2020) USA, Das et al. (2019) Asian emerging stock market, and Cheng and Chiu (2018) for 38 emerging countries.

AMG estimator indicates that a $1 \%$ rise in NREC will escalate EF by $13 \%$, whereas a $1 \%$ rise in REC will lessen the EF by $2 \%$. This argument is compatible with the conclusions reached by Destek and Sinha (2020) in the case of 24 OECD nations and Sharif et al. (2020) for Turkey. The impact of REC is significant and negative on the EF. This describes the clean role of REC in depleting the EF. The findings also expound that $\mathrm{E} 7$ economies are on the right track towards achieving the goal of development through the incorporation and progression of environmentally friendly advances. This is equivalent to the conclusion of Danish et al. (2020) for BRICS economies, Destek and Sinha (2020) for 24 OECD nations, Wang and Dong (2019) for 14 SSA countries, and Destek et al. (2018) for EU economies. A $1 \%$ rise in GPRI hinders EF by $10 \%$. As mentioned above, it is because of a decrease in production and consumption activities due to high GPRI. Also, GPRI creates uncertainty, which drives firms to put their tentative plans on hold and decrease current production to their limited capacity in anticipation to lower consumption. As GPRI has become the main indicator in economic and business cycles, significant players of economic activities including bankers, industrialists, and market traders accept that GPRI changes the element of the capital market and impedes the dynamics of investment (Caldara and Iacoviello 2018). Moreover, due to the negative and positive signs of GDP and GDP ${ }^{2}$, the current study validates the EKC for E7 countries. The other studies that confirm the existence of EKC include Al-Mulali and Ozturk (2016) for 27 advanced economies, Bilgili et al. (2016) for OECD nations, and Bölük and Mert (2015) for Turkey. In contrast, Al-Mulali and Ozturk (2015) in the case of 23 European economies do not support the presence of EKC.

The findings from the DH causality test highlight that there exists one-way causality running from GPRI to EF and from GPRI to $\mathrm{CO}_{2}$ emissions. This implies that GPR affects environmental degradation, but environmental degradation does not affect GPR in the selected countries. That is, environmental degradation is not one of the reasons behind geopolitical tensions, but GPR alters environmental degradation. Next, there exists one-way causality running from NREC to economic growth, indicating that non-renewables contribute to economic growth. However, economic growth does not affect NREC. Thus, the current study validates the growth hypothesis. Likewise, regarding the nexus between REC and economic growth, we also find the existence of a growth hypothesis. Hence, it could be concluded that E7 countries depend on energy consumption, and any action to conserve energy will affect economic growth.

\section{Conclusion}

The threat due to global warming and environmental degradation calls for investigating the socio-economic factors that drive these critical issues (i.e., global warming and environmental degradation). In the prior literature, economic growth and NREC have widely been probed as drivers of environmental degradation; however, there is a dearth of literature on the geopolitical risk-environment nexus. In addition, the limited literature on geopolitical risk-environment nexus has a contrasting conclusion that calls for further exploration of this line of research. Hence, this study probes the impact of GPR on environmental degradation, controlling the effects of economic growth, NREC, and REC in the case of E7 countries. This study contributes to the existing literature by using carbon emissions and EF as proxies for the environment in the case of $\mathrm{E} 7$ countries that provide robust findings. In addition, this study employs several second-generation panel data methods, AMG estimators, and DH causality tests for robust and reliable findings.

The empirical evidence shows that the data set has crosssectional dependence revealing spillover effects of macroeconomic shocks occurring in any of the countries. All variables are cointegrated which suggests that there exists an effective long-term connection among all the considered variables in the case of $\mathrm{E} 7$ countries. The long-run empirical estimates from AMG estimator show that there is a significant impact of NREC on environmental degradation; however, REC contributes to environmental improvements. This provides a solid argument that escalating REC helps decrease $\mathrm{CO}_{2}$ emissions. Secondly, results also depict that if GPR increases, it will reduce $\mathrm{CO}_{2}$ emissions. On the contrary, using $\mathrm{EF}$ as a proxy for environmental degradation, we report that NREC escalates EF and REC lessens the EF. Furthermore, results also depict that rise in GPR will tend to impede EF. The present study also confirms the presence of EKC for E7 countries. Findings from the causality test imply that GPR affects environmental degradation, but environmental degradation does not lead to geopolitical risk. 
Table.9 Findings from DH causality test using EF emissions as a proxy for environment

\begin{tabular}{|c|c|c|c|}
\hline Null hypothesis & Obs & $F$ statistic & Prob \\
\hline $\mathrm{GPRI}=>\mathrm{GDP}$ & 150 & 0.75714 & 0.3856 \\
\hline $\mathrm{GDP}=>\mathrm{GPRI}$ & 0.11763 & 0.7321 & \\
\hline $\mathrm{NREC}=>$ GDP & 150 & 13.8135 & $0.0003 * * *$ \\
\hline $\mathrm{GDP}=>\mathrm{NREC}$ & 0.73266 & 0.3934 & \\
\hline $\mathrm{REC}=>\mathrm{GDP}$ & 150 & 10.6580 & $0.0014 * * *$ \\
\hline $\mathrm{GDP}=>\mathrm{REC}$ & 1.24775 & 0.2658 & \\
\hline $\mathrm{EF}=>\mathrm{GDP}$ & 150 & 13.3061 & $0.0004 * * *$ \\
\hline $\mathrm{GDP}=>\mathrm{EF}$ & 38.2782 & 6.E-09*** & \\
\hline $\mathrm{NREC}=>$ GPRI & 150 & 4.18941 & $0.0425 * *$ \\
\hline GPRI $=>$ NREC & 1.28351 & 0.2591 & \\
\hline $\mathrm{REC}=>\mathrm{GPRI}$ & 150 & 4.99227 & $0.0270 * *$ \\
\hline $\mathrm{GPRI}=>\mathrm{REC}$ & 3.14574 & $0.0782 *$ & \\
\hline $\mathrm{EF}=>\mathrm{GPRI}$ & 150 & 0.00237 & 0.9613 \\
\hline $\mathrm{GPRI}=>\mathrm{EF}$ & 25.6840 & 1.E-06*** & \\
\hline $\mathrm{REC}=>\mathrm{NREC}$ & 150 & 4.37775 & $0.0381 * *$ \\
\hline $\mathrm{NREC}=>\mathrm{REC}$ & 5.01726 & $0.0266^{* *}$ & \\
\hline $\mathrm{EF}=>\mathrm{NREC}$ & 150 & 0.04967 & 0.8240 \\
\hline $\mathrm{NREC}=>\mathrm{EF}$ & 28.1238 & 4.E- $07 * * *$ & \\
\hline $\mathrm{EF}=>\mathrm{REC}$ & 150 & 1.51391 & 0.2205 \\
\hline $\mathrm{REC}=>\mathrm{EF}$ & 33.3736 & 4.E-08*** & \\
\hline
\end{tabular}

Moreover, we report the validity of the growth hypothesis (in the case of both renewable and non-renewable energy consumption) which is one-way causality running from NREC to economic growth.

The results suggest that to guarantee sustainable growth, E7 countries should invest in clean energies since global warming is becoming a more serious problem worldwide. Next, investment in REC is more proficient to limit $\mathrm{CO}_{2}$ emissions. Different sectors must be urged to adopt innovation that limits contaminations, and it will also help them to lessen their dependency on energy as well as to stimulate the energy security of countries that import energy. Furthermore, governments should provide subsidies on the import of renewable energy productions, as they ameliorate the environmental quality. There should be special research grants for renewable energy development. On the contrary, the government should impose high trade barriers on the import of non-renewable energy. Also, programs and schemes should be initiated to make people aware of the adverse effects of non-renewable energy use. Moreover, E7 countries are on the right track, as the findings from the EKC hypothesis suggest that high real income (above a threshold) leads to improved environmental quality. Further, we report that if governments try to reduce GPR, environmental degradation increases. Therefore, policymakers should keep in mind the environmental impacts of reducing GPR. In addition to this, if policymakers aim to reduce GPR and environmental degradation simultaneously, they should explore the other factors (e.g., renewables) that impede environmental degradation without affecting GPR. Moreover, policymakers should devise policies to encourage $R \& D$ investment, technological advancement, and green energy investment because these factors might curb environmental degradation without causing a surge in GPR. Additionally, at the time of low GPR, government officials and/or policymakers should divert their attention towards environmental degradation because low GPR leads to higher energy consumption and economic growth, which in turn deteriorate the environment. Apart from this, keeping in view the inverse relationship between GPR and the environment, higher environmental taxes should be imposed at times of high GPR and vice versa.

Regarding the limitations of this study, we analyze the emerging countries; so, this study does not propose any policy suggestions for developed countries. Next, the present study does not explain the country-wise findings on the relationship between GPRI and the environment. Regarding future research directions, researchers can explore the nexus between GPR and the environment in the case of developed countries. In terms of methodology, the non-linear or asymmetric impact of GPR on the environment could be examined. The direct and indirect impact of GPR on the environment can also be probed. Furthermore, structured machine learning panel data regression models can be used for future prediction to test the hypothesis related to GPR, carbon emissions, and environmental degradation.

\section{Appendix}

Table 10

Author contribution Iftikhar ul Husnain: supervision. Qasim Raza Syed: conceptualization and data analysis. Arooj Bashir: drafting.

M. A. Khan: drafting.

Data availability Available upon request.

\section{Declarations}

Ethics approval Not applicable.

Consent to participate Not applicable.

Consent for publication Not applicable.

Conflict of interest The authors declare no competing interests. 
Table.10 Variables with their measures and sources

\begin{tabular}{llll}
\hline Abbreviation & Indicator name & Measurement scale & Source \\
\hline$E F$ & Ecological footprint & Gha per person & GFN \\
$C O_{2}$ & $\mathrm{CO}_{2}$ emissions & Metric ton per capita & WDI \\
$G D P$ & GDP per capita & Constant 2010 \$US & WDI \\
$N R E C$ & Non-renewable energy consumption & Oil equivalent per capita & WDI \\
$R E C$ & Renewable energy consumption & Percentage of total final energy & WDI \\
$G P R I$ & Geopolitical risk index & Frequency of newspaper articles con- Polic- & yuncer- \\
& & taining "geopolitics"-related words & $\begin{array}{c}\text { yainty. } \\
\end{array}$ \\
& & & com \\
\hline
\end{tabular}

GFN, Global Footprint Network; WDI, World Development Indicators.

\section{References}

Abid M (2016) Impact of economic, financial, and institutional factors on $\mathrm{CO} 2$ emissions: evidence from Sub-Saharan Africa economies. Util Policy 41:85-94

Adams S, Adedoyin F, Olaniran E, Bekun FV (2020) Energy consumption, economic policy uncertainty and carbon emissions; causality evidence from resource rich economies. Econ Anal Policy 68:179-190

Akadiri S, Saint EKK, Akadiri AC, Avci T (2020) Does causality between geopolitical risk, tourism and economic growth matter? Evidence from Turkey. J Hosp Tour Manag 43:273-277. https:// doi.org/10.1016/j.jhtm.2019.09.002

Al Mamun M, Uddin GS, Suleman MT, Kang SH (2020) Geopolitical risk, uncertainty and Bitcoin investment. Physica A. Phys A Stat Mech Appl 540:123107

Al-Mulali U, Ozturk I (2015) The effect of energy consumption, urbanization, trade openness, industrial output, and the political stability on the environmental degradation in the MENA (Middle East and North African) region. Energy 84:382-389

Al-Mulali U, Ozturk I (2016) The investigation of environmental Kuznets curve hypothesis in the advanced economies: the role of energy prices. Renew Sustain Energy Rev 54:1622-1631. https:// doi.org/10.1016/j.rser.2015.10.131

Algamdi A, Brika SKM, Musa A, Chergui K (2021) COVID-19 deaths cases impact on oil prices: probable scenarios on Saudi Arabia economy. Frontiers in Public Health 9(6):620875

Ali S, Dogan E, Chen F, Khan Z (2020) International trade and environmental performance in top ten-emitters countries: the role of eco-innovation and renewable energy consumption. Sustainable Development.

Alola AA, Bekun FV, Sarkodie SA (2019) Dynamic impact of trade policy, economic growth, fertility rate, renewable and non-renewable energy consumption on ecological footprint in Europe. Sci Total Environ 685:702-709

Alsagr N, van Hemmen S (2021) The impact of financial development and geopolitical risk on renewable energy consumption: evidence from emerging markets. Environ Sci Pollut Res 28(20):25906-25919

Anser MK, Syed QR, Apergis N (2021a) Does geopolitical risk escalate $\mathrm{CO} 2$ emissions? Evidence from the BRICS countries. Environ Sci Pollut Res Int 28(35):48011-48021

Anser MK, Syed QR, Lean HH, Alola AA, Ahmad M (2021b) Do economic policy uncertainty and geopolitical risk lead to environmental degradation? Evidence from Emerging Economies Sustainability 13(11):5866

Anser MK, Apergis N, Syed QR et al (2021c) Exploring a new perspective of sustainable development drive through environmental Phillips curve in the case of the BRICST countries.
Environ Sci Pollut Res 28:48112-48122. https://doi.org/10.1007/ s11356-021-14056-5

Aruga K, Islam M, Jannat A (2020) Effects of COVID-19 on Indian energy consumption. Sustainability 12(14):5616

Ayoo C (2020) Towards energy security for the twenty-first century. Energy policy. Intech Open, London 15-40

Balcilar M, Bonato M, Gupta DR, R, (2018) Geopolitical risks and stock market dynamics of the BRICS. Econ Syst 42(2):295-306

Baloch MA, Wang B (2019) Analyzing the role of governance in $\mathrm{CO} 2$ emissions mitigation: the BRICS experience. Struct Chang Econ Dyn 51:119-125

Bello MO, Solarin SA, Yen YY (2018) The impact of electricity consumption on $\mathrm{CO} 2$ emission, carbon footprint, water footprint and ecological footprint: the role of hydropower in an emerging economy. J Environ Manage 219:218-230. https://doi.org/10. 1016/j.jenvman.2018.04.101

Bildirici M (2017a) CO2 emissions and militarization in G7 countries: panel cointegration and trivariate causality approaches. Environ Dev Econ 22(6):771

Bildirici M (2017b) The causal link among militarization, economic growth, CO 2 emission, and energy consumption. Environ Sci Pollut Res 24(5):4625-4636

Bildirici M (2017c) The effects of militarization on biofuel consumption and CO2 emission. J Clean Prod 152:420-428

Bildirici M (2020) Terrorism, environmental pollution, foreign direct investment (FDI), energy consumption, and economic growth: Evidences from China, India, Israel, and Turkey. Energy \& Environment 0958305X20919409

Bildirici M, Gokmenoglu SM (2020) The impact of terrorism and FDI on environmental pollution: evidence from Afghanistan, Iraq, Nigeria, Pakistan, Philippines, Syria, Somalia, Thailand and Yemen. Environ. Impact Assess. Rev 81:106340

Bilgili F, Koçak E, Bulut Ü (2016) The dynamic impact of renewable energy consumption on $\mathrm{CO} 2$ emissions: a revisited environmental Kuznets curve approach. Renew Sustain Energy Rev 54:838-845. https://doi.org/10.1016/j.rser.2015.10.080

Bhowmik R, Syed QR, Apergis N et al (2021) Applying a dynamic ARDL approach to the Environmental Phillips Curve (EPC) hypothesis amid monetary, fiscal, and trade policy uncertainty in the USA. Environ Sci Pollut Res. https://doi.org/10.1007/ s11356-021-16716-y

Bölük G, Mert M (2015) The renewable energy, growth and environmental Kuznets curve in Turkey: an ARDL approach. Renew Sustain Energy Rev 52:587-595. https://doi.org/10.1016/j.rser. 2015.07.138

Bompard E, Carpignano A, Erriquez M, Grosso D, Pession M, Profumo F (2017) National energy security assessment in a geopolitical perspective. Energy 130:144-154 
Bouoiyour J, Selmi R, Hammoudeh S, Wohar ME (2019) What are the categories of geopolitical risks that could drive oil prices higher? Acts or threats? Energy Economics 84:104523

Cai Y, Wu Y (2020) Time-varying interactions between geopolitical risks and renewable energy consumption. Int Rev Econ Financ 74:116-137

Caldara D, Iacoviello M (2018) Measuring geopolitical risk. FRB International Finance Discussion Paper(1222)

Cheng CHJ, Chiu CW (2018) How important are global geopolitical risks to emerging countries? Int Econ 156:305-325. https://doi. org/10.1016/j.inteco.2018.05.002

Danish U, Recep Khan SUD (2020) Determinants of the ecological footprint: role of renewable energy, natural resources, and urbanization. Sustain. Cities Soc 54:101996

Das D, Kannadhasan M, Bhattacharyya M (2019) Do the emerging stock markets react to international economic policy uncertainty, geopolitical risk and financial stress alike? North Am J Econ Finance 48:1-19

Destek A, Sarkodie SA (2019) Investigation of environmental Kuznets curve for ecological footprint: the role of energy and financial development. Sci Total Environ 650:2483-2489

Destek A, Sinha A (2020) Renewable, non-renewable energy consumption, economic growth, trade openness and ecological footprint: evidence from organisation for economic co-operation and development countries. J. Clean. Prod 242:118537

Destek A, Ulucak R, Dogan E (2018) Analyzing the environmental Kuznets curve for the EU countries: the role of ecological footprint. Environ Sci Pollut Res 25(29):29387-29396. https://doi. org/10.1007/s11356-018-2911-4

Dogan E, Aslan A (2017) Exploring the relationship among CO2 emissions, real GDP, energy consumption and tourism in the EU and candidate countries: evidence from panel models robust to heterogeneity and cross-sectional dependence. Renew SustainEnergy Rev 77:239-245

Dogan E, Majeed MT, Luni T (2021) Analyzing the impacts of geopolitical risk and economic uncertainty on natural resources rents. Resources Policy 72:102056

Dogan E, Seker F (2016) The influence of real output, renewable and non-renewable energy, trade and financial development on carbon emissions in the top renewable energy countries. Renew Sustain Energy Rev 60:1074-1085

Gardiner R, Hajek P (2020) Interactions among energy consumption, $\mathrm{CO} 2$, and economic development in European Union countries. Sustain Dev 28(4):723-740

Gorus MS, Aydin M (2019) The relationship between energy consumption, economic growth, and $\mathrm{CO} 2$ emission in MENA countries: causality analysis in the frequency domain. Energy 168:815-822. https://doi.org/10.1016/j.energy.2018.11.139

Hacrimamoğlu T, Sandalcılar AR (2020) The effect of renewable energy consumption on economic stability: panel data analysis on selected countries. EMAJ. Emerg Mark Rev 10(1):10-20. https://doi.org/10.5195/emaj.2020.201

Haider A, Bashir A, Husnain MI (2020) Impact of agricultural land use and economic growth on nitrous oxide emissions: evidence from developed and developing countries. Sci. Total Environ $741: 140421$

Hanif I, Aziz B, Chaudhry IS (2019) Carbon emissions across the spectrum of renewable and nonrenewable energy use in developing economies of Asia. Renewable Energy 143:586-595. https:// doi.org/10.1016/j.renene.2019.05.032

Hashmi SM, Bhowmik R, Inglesi-Lotz R, Syed QR (2021) Investigating the Environmental Kuznets Curve hypothesis amidst geopolitical risk: Global evidence using bootstrap ARDL approach. Environ Sci Pollut Res 1-14

Inglesi-Lotz R, Dogan E (2018) The role of renewable versus nonrenewable energy to the level of $\mathrm{CO} 2$ emissions a panel analysis of sub-Saharan Africa's Big 10 electricity generators. Renewable Energy 123:36-43

Iqbal S, Bilal AR, Nurunnabi M, Iqbal W, Alfakhri Y, Iqbal N (2021) It is time to control the worst: testing COVID-19 outbreak, energy consumption and CO 2 emission. Environ Sci Pollut Res 28(15):19008-19020

Kannadhasan M, Das D (2020) Do Asian emerging stock markets react to international economic policy uncertainty and geopolitical risk alike? A quantile regression approach. Finance Res Letters 34:101276

Le HP, Bao HHG (2020) Renewable and nonrenewable energy consumption, government expenditure, institution quality, financial development, trade openness, and sustainable development in Latin America and Caribbean emerging market and developing economies. Int. J. Energy Econ 10(1):242-248. https://doi.org/ 10.32479/ijeep. 8506

Lokhandwala S, Gautam P (2020) Indirect impact of COVID-19 on environment: a brief study in Indian context. Environment Res 188:109807

Mehdi BJ, Slim BY (2017) The role of renewable energy and agriculture in reducing $\mathrm{CO} 2$ emissions: evidence for North Africa countries. Ecol Ind 74(68477):295-301. https://doi.org/10. 1016/j.ecolind.2016.11.032

Muhammad S, Long X (2021) Rule of law and CO2 emissions: a comparative analysis across 65 belt and road initiative (BRI) countries. J Clean Prod 279:123539

Nathaniel SP, Iheonu CO (2019) Carbon dioxide abatement in Africa: the role of renewable and non-renewable energy consumption. Sci Total Environ 679:337-345

Nathaniel S, Khan SAR (2020) The nexus between urbanization, renewable energy, trade, and ecological footprint in ASEAN countries. J Clean Prod 272:122709. https://doi.org/10.1016/j. jclepro.2020.122709

Olanipekun IO, Alola AA (2020) Crude oil production in the Persian Gulf amidst geopolitical risk, cost of damage and resources rents: is there asymmetric inference? Resour Policy 69:101873

Pesaran MH (2007) A simple panel unit root test in the presence of cross-section dependence. J Appl Economet 22(2):265-312

PricewaterhouseCoopers (2018) 21st Annual Global CEO Survey.

Qin Y, Hong K, Chen J, Zhang Z (2020) Asymmetric effects of geopolitical risks on energy returns and volatility under different market conditions. Energy Econo 90:104851

Rasoulinezhad E, Taghizadeh-Hesary F, Sung J, Panthamit N (2020) Geopolitical risk and energy transition in Russia: evidence from ARDL bounds testing method. Sustainability 12(7):2689

Sarkodie SA, Adams S (2018) Renewable energy, nuclear energy, and environmental pollution: accounting for political institutional quality in South Africa. Sci Total Environ 643:1590-1601

Shafiei S, Salim RA (2014) Non-renewable and renewable energy consumption and $\mathrm{CO} 2$ emissions in OECD countries: a comparative analysis. Energy Policy 66:547-556. https://doi.org/10.1016/j. enpol.2013.10.064

Shahbaz M, Haouas I, Hoang TH, Van, (2019) Economic growth and environmental degradation in Vietnam: is the environmental Kuznets curve a complete picture? Emerg Mark Rev 38:197-218. https://doi.org/10.1016/j.ememar.2018.12.006

Sharif A, Raza SA, Ozturk I, Afshan S (2019) The dynamic relationship of renewable and nonrenewable energy consumption with carbon emission: a global study with the application of heterogeneous panel estimations. Renewable Energy 133:685-691. https:// doi.org/10.1016/j.renene.2018.10.052

Sharif A, Baris-Tuzemen O, Uzuner G, Ozturk I, Sinha A (2020) Revisiting the role of renewable and non-renewable energy consumption on Turkey's ecological footprint: evidence from quantile ARDL approach. Sustainable Cities and Society, 102138. Renewable energy consumption reduce ecological footprint? Evidence from 
eight developing countries of Asia. J Clean Prod 285:104277. https://doi.org/10.1016/j.jclepro.2020.124867

Sharma R, Sinha A, Kautish P (2021) Does renewable energy consumption reduce ecological footprint? Evidence from eight developing countries of Asia. J Clean Prod 285:124867

Sinha A, Gupta M, Shahbaz M, Sengupta T (2019) Impact of corruption in public sector on environmental quality: implications for sustainability in BRICS and next 11 countries. J Clean Prod 232:1379-1393. https://doi.org/10.1016/j.jclepro.2019.06.066

Sinha A, Shahbaz M, Balsalobre D (2017) Exploring the relationship between energy usage segregation and environmental degradation in N-11 countries. J Clean Prod 168:1217-1229. https://doi.org/ 10.1016/j.jclepro.2017.09.071

Sweidan OD (2021) The geopolitical risk effect on the US renewable energy deployment. Journal of Cleaner Production 293: 126189

Syed QR, Bouri E (2021) Impact of economic policy uncertainty on $\mathrm{CO} 2$ emissions in the US: evidence from bootstrap ARDL approach. Journal of Public Affairs e2595

Syed QR, Bouri E, Zafar RF, Adekoya OB (2021) Does geopolitical risk mitigate inbound tourism? Evidence from panel quantile regression. J Public Aff e2784

Tuna G, Tuna VE (2019) The asymmetric causal relationship between renewable and non-renewable energy consumption and economic growth in the ASEAN-5 countries. Resour Policy 62:114-124. https://doi.org/10.1016/j.resourpol.2019.03.010

Wang J, Dong K (2019) What drives environmental degradation? Evidence from 14 Sub-Saharan African countries. Sci Total Environ 656:165-173. https://doi.org/10.1016/j.scitotenv.2018.11.354

Wang Q, Su M (2020) A preliminary assessment of the impact of COVID-19 on environment-a case study of China. Science of the total environment 728:138915
Warr BS, Ayres RU (2010) Evidence of causality between the quantity and quality of energy consumption and economic growth. Energy 35(4):1688-1693

Westerlund J (2007) Testing for error correction in panel data. Oxford Bull Econ Stat 69(6):709-748

Yergin D (2006) Ensuring energy security. Foreign affairs 8(69):82

Zafar MW, Mirza FM, Zaidi SAH, Hou F (2019) The nexus of renewable and nonrenewable energy consumption, trade openness, and $\mathrm{CO} 2$ emissions in the framework of EKC: evidence from emerging economies. Environ Sci Pollut Res 26(15):15162-15173. https://doi.org/10.1007/s11356-019-04912-w

Zhang Z, Xi L, Bin S, Yuhuan Z, Song W, Ya L, Hao L, Yongfeng Z, Ashfaq A, Guang S (2019) Energy, CO2 emissions, and value added flows embodied in the international trade of the BRICS group: a comprehensive assessment. Renew Sustain Energy Rev 116:109432. https://doi.org/10.1016/j.rser.2019.109432

Zhao W, Zhong R, Sohail S, Majeed MT, Ullah S (2021) Geopolitical risks, energy consumption, and $\mathrm{CO} 2$ emissions in BRICS: an asymmetric analysis. Environ Sci Pollut Res Int 28(29):39668-39679

Publisher's note Springer Nature remains neutral with regard to jurisdictional claims in published maps and institutional affiliations. 